TI 2015-016/VI

Tinbergen Institute Discussion Paper

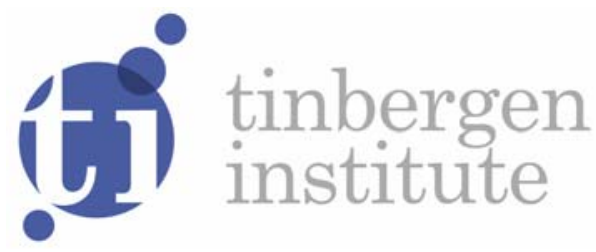

\title{
On-the-Job Search and City Structure
}

\author{
Aico van Vuuren
}

Faculty of Economics, VU University Amsterdam, and Tinbergen Institute, the Netherlands. 
Tinbergen Institute is the graduate school and research institute in economics of Erasmus University Rotterdam, the University of Amsterdam and VU University Amsterdam.

More TI discussion papers can be downloaded at http://www.tinbergen.nl

Tinbergen Institute has two locations:

Tinbergen Institute Amsterdam

Gustav Mahlerplein 117

1082 MS Amsterdam

The Netherlands

Tel.: +31(0)205251600

Tinbergen Institute Rotterdam

Burg. Oudlaan 50

3062 PA Rotterdam

The Netherlands

Tel.: +31(0)10 4088900

Fax: $+31(0) 104089031$

Duisenberg school of finance is a collaboration of the Dutch financial sector and universities, with the ambition to support innovative research and offer top quality academic education in core areas of finance.

DSF research papers can be downloaded at: http://www.dsf.nl/

Duisenberg school of finance

Gustav Mahlerplein 117

1082 MS Amsterdam

The Netherlands

Tel.: +31(0)20 5258579 


\title{
On-the-job search and city structure*
}

\author{
Aico van Vuuren ${ }^{\dagger}$
}

Version: January 2015

\begin{abstract}
We investigate an equilibrium search model in which the search frictions are increasing with the distance to the central business district allowing for on-the-job search and endogenous (monopsony) wage formation and land allocation. We find that there are many different possible outcomes with respect to the location of unemployed workers within a metropolitan area. The city structure of the decentralized market is only efficient when commuting costs of the employed workers are large. Policies reducing the rental costs of unemployed workers for locations close to the central business district can potentially increase welfare.
\end{abstract}

\footnotetext{
*We would like to thank Yves Zenou, Jos van Ommeren as well as participants of the Search and Matching Conference in Edinburgh and the workshop on labor mobility in Louvain-la-Neuve in particular Paul Beaudry and Etienne Wasmer for useful comments.

${ }^{\dagger}$ VU University Amsterdam and Tinbergen Institute. Keywords: Search, city structure, urban economics
} 


\section{Introduction}

This paper investigates the city structure extending the mono-centric city model of Wasmer and Zenou (2002) by including on-the-job search and endogenous wage formation. Wasmer and Zenou (2002) found that there are two mutually exclusive equilibrium city structures in the absence of on-the-job search and assuming exante homogeneous workers. In the first city structure, unemployed workers live as close as possible to the central business district (CBD), while employed workers live farther away. This equilibrium exists whenever the level of search frictions is low. They call this the integrated city equilibrium. Another city structure occurs in the case of high search frictions. In that case the unemployed live as far as possible from the CBD (and hence pay low rents), while the employed workers are centrally located. They call this the segregated city equilibrium. In this paper, we find that these two equilibria are special cases of a large range of equilibria depending on the location of the unemployed. We find that neither an integrated nor a segregated city is formed when the distance dependent search efficiency of employed workers is identical to that of unemployed workers while their commuting costs are low. Instead, we obtain an internal solution of the decentralized market in which low paid workers are located the closest to the $\mathrm{CBD}$, while high paid workers are located the farthest away from that district. The unemployed are located in between these two groups of workers.

We find the decentralized market outcome to be inefficient under very general circumstances. The externality comes from the wrong incentives of the low paid workers. These workers want to locate themselves close to the CBD in order 
to obtain a job in which they receive a higher wage. However, since we assume homogeneity in productivity of the worker and firm matches in our basic analysis, social welfare is not affected by a job-to-job transition, but only by a transition of a worker from unemployment into a paid job. Therefore, the social planner prefers a situation in which the unemployed workers are located at a closer distance to the CBD than the market. In terms of the decision of location, the worker incentives in the market are only in line with the maximization of social welfare when wages are equal to their productivity. As such, the monoposony power of the firms is the single determinant for the externality. However, this monoposony power is also necessary for firms to open vacancies and hire workers in the first place. Hence, the market can never result in an efficient outcome. We show as a robustness check that the assumption of homogeneneity in productivity of job matches is not essential to obtain this result.

We close our model assuming that firms post wages as in Burdett and Mortensen (1998). Most of our results are not dependent on this assumption, while the remaining results can be adapted to other wage-setting mechanisms, conditional on the assumption that monopsony wages are paid. There is one good reason to focus on wage-posting models: abstracting from endogenous land allocation, Gautier et al. (2010) look at many different wage-setting mechanisms such as wage posting, bargaining and at models with the opportunity to re-negotiate using outside offers. They show that among these models, wage posting is the only framework in which the market outcome can be constrained efficient. As we show that even wage-posting models can never result in an efficient allocation, 
our inefficiencies must be due to endogenous land allocation.

Our paper makes a case for the presence of subsidized housing for the unemployed workers. Social welfare can increase in the case that unemployed workers are rewarded for living closer to the CBD. However, such subsidies should be based on employment status and not on earned income and should terminate directly after the acceptance of a job. We also find that the potential gains for such a policy are limited: our simulation exercises indicate that the inefficiencies that result from endogenous land allocation are only around 1 percent of the total loss of production due to search frictions.

Our paper is closely related to Kawata and Sato (2012) who also extend the model of Wasmer and Zenou (2002) including on-the-job search. There are two important differences. First, we use other assumptions on how wages are offered to workers. ${ }^{1}$ Second, they assume search effort to be independent of distance to the $\mathrm{CBD}$ which implies that unemployed workers are always located the farthest away from the CBD (due to the higher commuting costs of the employed workers).

The remainder of this paper is set up as follows. The next section looks at some facts about city structures. Section 3 sets up the model and Section 4 looks at the partial equilibrium. Section 5 looks at the wage-setting mechanism and Section 6 looks at the general equilibrium. Section 7 looks at the social planner while Section 8 calibrates the model. Section 9 discusses our results and looks at potential extensions and Section 10 concludes.

\footnotetext{
${ }^{1}$ More in particular they use the competitive search framework of Garibaldi and Moen (2010) and the directed search framework of Menzio and Shi (2011).
} 


\section{Empirical evidence from city structures}

The location of the unemployed within a city and the distance to potential jobs is well described in the somewhat competing literature of the spatial mismatch hypothesis and residential segregation. ${ }^{2}$ Gobillon et al. (2007) provide a recent overview of the present state of the literature which is dominated by papers that are well fit for the US where the majority of cities is decentralized. There is not a lot of evidence from Europe where cities are still very centralized but exceptions are Van der Klaauw and Van Ours (2003), Dujardin et al. (2008), Gobillon et al. (2010) and Åslund et al. (2010). Although Dujardin et al. (2008) conclude that the inner city of Brussels is largely dominated by zones with high unemployment rates, they also find that the inner city hosts many zones with high job densities, in some cases even the same zones as the ones with high levels of unemployment. Gobillon et al. (2010) investigate the inner city of Paris and conclude that the highest unemployment rates in Paris are located close to the CBD of Paris. However, unemployment rates in the CBD itself are lower than the metropolitan average. Finally, Åslund et al. (2010) find that for Stockholm the highest job density can be found in the CBD and that unemployment rates are especially high in the suburban areas around that district.

A similar picture can be derived for the city of Amsterdam. The job density

\footnotetext{
${ }^{2}$ The difference between these two hypotheses is the causality for segregation. The spatial mismatch hypothesis takes the location as exogenous and explains why many low educated (especially Afro-American) workers are isolated from jobs. The residential segregation literature takes the labor market status as exogenous and explains why low skilled (and culturally connected) workers are living together in poor areas.
} 
of Amsterdam is the highest in its historical center and is much lower in the zones around that district. The only exception is the southern financial district. The density of welfare recipients within the city borders of Amsterdam was 7.4 percent in 2012, which was twice as high as the countrywide average of 3.7 percent. The municipalities that have a border with Amsterdam face welfare recipiency rates in between 1.0 and 3.4 percent. The picture within the city borders of the municipality of Amsterdam is mixed. The neighborhoods within the historical center have welfare recipiency rates up to at most 2 percent and a similar picture is found for the southern part of the city. The other neighborhoods close to the city center are the economically least advantaged with welfare recipiency rates sometimes over 10 percent.

The first column of Table 1 reports the results of a regression of the welfare recipiency rate on the distance and its square. We find that the second order term of distance is negative and significant, while the first order term is positive (but not significant). Moreover, we find that the largest welfare recipiency rate is located at a distance of 3.7 miles from the city center. Using the financial district in the south as central district does not affect our results. These conclusions are not derived from the fact that urban areas around the city center are not very popular residential areas: the second column of Table 1 presents the results of a regression of the log monthly rental price on a couple of characteristics of the house including the distance of the neighborhood of the house with the CBD. Both distance and distance squared are negative and significant and hence the farther away is the area, the lower is the rental price. This implies that the 


\begin{tabular}{lrr}
\hline \hline Variable & $\begin{array}{r}\text { Welfare recipiency } \\
\text { rate }\end{array}$ & $\begin{array}{r}\text { Rental price } \\
\text { (in logs) }\end{array}$ \\
\hline \hline Constant & 3.88 & 5.91 \\
& $(0.892)$ & $(0.0003)$ \\
Distance & 0.554 & -0.0272 \\
& $(0.438)$ & $(0.007)$ \\
Distance $^{2}$ & -0.077 & -0.004 \\
& $(0.042)$ & $(0.001)$ \\
$R^{2}$ & & \\
Number of observations & 0.055 & 0.797 \\
\hline \hline
\end{tabular}

Table 1: Regression results. $\mathrm{CBD}$ is defined as the central square (Dam square) and distances are based on minimum road distance from http://www.afstandmeten.nl/. Welfare recipiency rate is based on total number of welfare receivers divided by the population between 15 and 55 and comes from the statistical office of the municipality of Amsterdam, see http://www.os.amsterdam.nl/. Rental prices are asking prices for non-regulated residential property in Amsterdam. Source: http://www.funda.nl/. We also include size, size ${ }^{2}$ and number of rooms in this regression.

areas around the city center are lower priced than the areas in the CBD, but still higher priced than the even farther areas which have economically much better conditions.

The conclusion that can be drawn from the previous paragraphs is that city structures are mixed in Europe and that a simple distinction between integrated and segregated is not sufficient. This paper attempts to explain these differences based on on-the-job search. Still, the city structure in many European cities may also be formed by governmental policies. Therefore, some inner city residents may have chosen their locations based on low rental prices rather than a high job density. On the other hand, there are many opportunities for the unemployed 
poor to live farther from the city center. For example, the unemployed have the opportunity to settle in governmental housing all over the Netherlands and apart from housing (which has a regulated fixed price), cities are usually expensive and hence unattractive for poor families. Instead of using all determinants that can explain a particular city structure, this paper focuses on one aspect of cities being increased job opportunities.

\section{The Model}

\subsection{General notation and assumptions}

We assume that the total number of workers equals unity and workers are uniformly located along a linear, closed and mono-centric city. ${ }^{3}$ Time is continuous and land is owned by absentee landlords. We define $\mu$ as the total number of matches per unit of labor supply, $u$ is the unemployment rate and $v$ is total number of vacancies. Moreover, we define $d ; 0 \leq d \leq 1$ as the distance to the central business district (CBD). Let $s(d)$ be the search efficiency of an unemployed worker at distance $d$. As in Wasmer and Zenou (2002), we assume the following function

$$
s(d)=s_{0}-a d,
$$

where $s_{0}$ and $a$ are relative efficiency parameters and $s_{0} \geq a$ since otherwise some workers would have negative search efficiency. Moreover, we assume that the search efficiency of the employed workers at distance $d$ equals $\psi s(d), 0 \leq \psi \leq 1$.

\footnotetext{
${ }^{3}$ see Zenou, 2009 for an explanation of these terms.
} 
The parameter $\psi$ is relative search efficiency of employed workers. Workers and jobs arrive according to a Poisson process.

We assume a general expression for the contact technology between job seekers and vacancies (Gautier et al., 2010)

$$
\mu=\alpha\left[s\left(\bar{d}_{u}\right) u+(1-u) \psi s\left(\bar{d}_{e}\right)\right]^{\nu} v^{\xi},
$$

where $\bar{d}_{u}$ and $\bar{d}_{e}$ are the average distance to the CBD of respectively the unemployed and employed workers. The parameters $\nu, 0 \leq \nu \leq 1$ and $\xi, 0 \leq \xi \leq 1$ measure the relative contributions of job seekers and vacancies to the contact technology. The parameter $\alpha$ measures the overall efficiency of the matching process. Let $\lambda:=\alpha\left[s\left(\bar{d}_{u}\right) u+(1-u) \psi s\left(\bar{d}_{e}\right)\right]^{\nu-1} v^{\xi}$. The implied contact rates for unemployed and employed workers are $\lambda s(d)$ and $\lambda \psi s(d)$.

Vacancies can be opened by firms with a per-period cost equal to $\gamma$. We assume $\tau \geq 0$ to be the commuting costs at distance $d$ from the CBD for employed individuals. Without loss of generality, we set the transportation costs of the unemployed equal to zero. In addition, we denote the land rent at distance $d$ as $R(d)$ and denote $R(1)=R_{A}$ as the exogenous rental costs of agricultural land. We assume that workers produce $b$ in case of unemployment and $p$ in case that they are matched to an employer. We assume that $p-b>\tau$ in order to obtain sensible equilibriums in which unemployed workers accept jobs. Wages are denoted by $w$. The wage-offer distribution of firms is denoted by $F$. We denote the distribution of wages among employed workers by $G$ and we assume that matches are destroyed with an exogenous job destruction rate equal to $\delta$. 


\section{$3.2 \quad$ Workers}

Define $V_{u}(d)$ as the life-time discounted value of a worker that is unemployed and living at distance $d$ from the CBD and denote $V_{e}(d, w)$ as the life-time discounted value of an employed worker also living at distance $d$ from the CBD and working with a wage equal to $w$. We obtain the following Bellman equations

$$
\rho V_{u}(d)=b-R(d)+\lambda s(d) \int_{\varphi}^{\bar{w}}\left(\max _{d^{\prime}} V_{e}\left(d^{\prime}, w\right)-V_{u}(d)\right) d F(w)
$$

and

$$
\begin{aligned}
\rho V_{e}(d, w)= & w-\tau d-R(d)+\lambda \psi s(d) \int_{w}^{\bar{w}}\left(\max _{d^{\prime}} V_{e}\left(d^{\prime}, x\right)-V_{e}(d, w)\right) d F(x) \\
& +\delta\left(\max _{d^{\prime}} V_{u}\left(d^{\prime}\right)-V_{e}(d, w)\right)
\end{aligned}
$$

where $\varphi$ is the reservation wage of the unemployed and $\bar{w}$ is the upper bound of the support of the wage offer distribution. Unemployed workers receive their home production every period minus their rental costs. In addition, they have the possibility to receive a job offer (with a rate equal to $\lambda s(d)$ ) and that job offer is accepted whenever the value of acceptance is larger than the value to reject the job offer. Employed workers receive their wages minus the sum of the transport and rental costs. They also have the possibility to receive a job offer and if a job offer is received, they accept it when the value is higher. Finally, they have the possibility to lose their jobs and in that case they receive the value of an unemployed worker. 


\subsection{Firms}

We define $V_{v}(w)$ as the value of a firm that opens a vacancy that pays $w$ in the case of a match and $V_{j}(w)$ is the value of a match that pays wage $w$. We obtain

$$
\rho V_{v}(w)=\frac{\lambda}{v}\left(u s\left(\bar{d}_{u}\right)+(1-u) \psi \int_{\inf \{\mathcal{G}\}}^{w} s\left(\bar{d}_{e}(x)\right) d G(x)\right) V_{j}(w)-\gamma
$$

where $\bar{d}_{e}(w)$ is defined as the average distance to the CBD of an employed worker that earns $w$ and $\mathcal{G}$ is the support of $G$. The left-hand side of equation (5) can be explained as follows: the value of a vacancy equals the rate at which a match is formed multiplied by the value of a match, i.e. $V_{j}(w)$. In addition, we have to subtract from this the costs of keeping a vacancy open, i.e. $\gamma$. A match is formed when the firm meets either an unemployed worker or an employed that earns $w$ or less. Hence, the rate in which a match is formed is the sum of the rates of these two events. Taking into account that matching is random, these rates can be shown to equal $\lambda u s\left(\bar{d}_{u}\right) / v$ and $\lambda(1-u) \int_{\inf \{\mathcal{G}\}}^{w} \bar{d}_{e}(x) d G(x) / v$ for unemployed and employed workers. The value of a match can be calculated by its Bellman equation and after rewriting, we obtain

$$
V_{j}(w)=\frac{p-w}{\left.\rho+\delta+\lambda \psi s\left(\bar{d}_{e}(w)\right)\right) \bar{F}(w)} .
$$

Hence, the value of a match equals the properly discounted flow of profits, taking into account that a match can be ended by either exogenous reasons, which happens with a rate equal to $\delta$, or because the worker finds a better match, which happens with a rate equal to $\lambda \psi s\left(\bar{d}_{e}(w)\right)$. 


\subsection{Wage-setting mechanism}

We make three assumptions for the wage offer distribution $F$ : (i) it does not have any mass points, (ii) the lowest offered wage equals the reservation wage of the unemployed workers, (iii) $\bar{w}<p$. Many monoposony models have this property, such as wage-posting models (Burdett and Mortensen, 1998) and wage bargaining models with on-the-job search (Shimer, 2006). Gautier et al. (2010) give an overview of these models. Many of our results are not dependent on the exact structure of the wage offer distribution as long as the three conditions are satisfied. We illustrate the role of the wage-setting mechanism in Section 5.

\section{Partial equilibrium}

\subsection{Partial equilibrium at the housing market}

As in Wasmer and Zenou (2002), we can use the condition that in the absence of relocation costs unemployed workers should have the same value independent of the distance to the CBD. Otherwise, some unemployed workers may be able to relocate themselves and gain in terms of utility and this cannot be an equilibrium. Hence, we must have that $V_{u}(d)=\bar{V}_{u}$ for the value of the unemployed. Likewise, we have that employed workers with a wage $w$ should receive the same value as well, i.e. $V_{e}(d, w)=\bar{V}_{e}(w)$. Moreover, define the bid-rent function $\Psi_{u}(d)$ as the maximum rent that an unemployed worker is able to pay for residing at distance $d$ from the CBD in order to obtain the value $\bar{V}_{u}$. Likewise, we define the bid-rent 
function $\Psi_{e}(d, w)$ for the employed workers. ${ }^{4}$ Based on equation (3), we obtain

$$
\Psi_{u}(d)=b+\lambda s(d) \int_{\varphi}^{\bar{w}}\left(\bar{V}_{e}(w)-\bar{V}_{u}\right) d F(w)-\rho \bar{V}_{u}
$$

Likewise, define the bid-rent function $\Psi_{e}(d, w)$. Based on equation (4), we obtain

$$
\begin{aligned}
\Psi_{e}(d, w)= & w-\tau d+\lambda \psi s(d) \int_{w}^{\bar{w}}\left(\bar{V}_{e}(x)-\bar{V}_{e}(w)\right) d F(x) \\
& +\delta\left(\bar{V}_{u}-\bar{V}_{e}(w)\right)-\rho \bar{V}_{e}(w)
\end{aligned}
$$

The (partial) derivatives of the bid rents $\Psi_{u}, \Psi_{e}$ with respect to $d$ can be obtained by taking derivatives of these values, i.e.

$$
\Psi_{u}^{\prime}(d)=-a \lambda \int_{\varphi}^{\bar{w}}\left(\bar{V}_{e}(w)-\bar{V}_{u}\right) d F(w)
$$

and

$$
\frac{\partial \Psi_{e}(d, w)}{\partial d}=-\tau-a \lambda \psi \int_{w}^{\bar{w}}\left(\bar{V}_{e}(x)-\bar{V}_{e}(w)\right) d F(x)
$$

Note that both derivatives are negative. As in Wasmer and Zenou (2002), the second order derivatives with respect to $d$ equal zero. The cross-partial derivative equals

$$
\frac{\partial^{2} \Psi_{e}(d, w)}{\partial d \partial w}=a \lambda \psi \frac{\partial \bar{V}_{e}(w)}{\partial w}(1-F(w))
$$

which is strictly negative for all $w<\bar{w}$. Workers with higher employment levels have less to gain by moving closer to the CBD since the likelihood of obtaining even better job offers declines with the wage level. The distribution of land is

\footnotetext{
${ }^{4}$ The concept of bid rents is now standard in urban economics and therefore we do not elaborate on it. See Fujita, 1989, Zenou 2009 for detailed descriptions of the concept of bid rent. Also note that this is somewhat abusive notation since $\Psi_{u}$ also depends on $\bar{V}_{u}$ and $\bar{V}_{e}(w) ; \varphi \leq w \leq \bar{w}$.
} 
now determined by the workers who have the highest bid rent. Let $\mathcal{W}(d)$ be the set of wages observed by workers with distance $d$, or

$$
\mathcal{W}(d)=\left\{w \mid \forall w^{\prime} \in[\varphi, \bar{w}]: \Psi_{e}(d, w) \geq \Psi_{e}\left(d, w^{\prime}\right) \wedge \Psi_{e}(d, w) \geq \Psi_{u}(d)\right\}
$$

Note that this set can be empty in the case that the willingness to pay for the unemployed is strictly larger. In addition, $\mathcal{W}(d)$ should have measure zero since $d$ has measure zero. Hence, $\mathcal{W}(d)$ cannot be an interval. The following lemma states that the sets must be strictly increasing in $d$.

Lemma 1 Suppose that we have $d_{1}, d_{2} \in[0,1]$ and $d_{1}<d_{2}$. Then for any $w_{1} \in \mathcal{W}\left(d_{1}\right)$ and $w_{2} \in \mathcal{W}\left(d_{2}\right)$ we have $w_{1}<w_{2}$

\section{Proof: See Appendix A.}

A direct result of Lemma 1 together with the non-interval restriction of $\mathcal{W}(d)$ is that $\mathcal{W}(d)$ is single valued and therefore we denote $w(d)=\mathcal{W}(d)$. We use $d(w)=\bar{d}_{e}(w)$ for its inverse. Partial integration of the integral in (7) and taking derivatives of the left- and right-hand side of equation (4), we obtain the following first-order derivative of the bid-rent function for unemployed workers ${ }^{5}$

$$
\Psi_{u}^{\prime}(d)=-a \lambda \int_{\varphi}^{\bar{w}}\left[\frac{\bar{F}(w)}{\rho+\delta+\lambda \psi s(d(w)) \bar{F}(w)}\right] d w
$$

and

$$
\frac{\partial \Psi_{e}(d, w)}{\partial d}=-\tau-a \lambda \psi \int_{w}^{\bar{w}}\left[\frac{\bar{F}(x)}{\rho+\delta+\lambda \psi s(d(x)) \bar{F}(x)}\right] d x .
$$

${ }^{5}$ Note that $\bar{V}_{e}^{\prime}(w)=\frac{\partial V_{e}(w, d(w))}{\partial w}+\frac{\partial V_{e}(w, d(w))}{\partial d} d^{\prime}(w)=\frac{\partial V_{e}(w, d(w))}{\partial w}$, where the last equality holds due to the first-order condition of $V_{e}$ with respect to $d$. 
We define the set of distances at which the unemployed workers are living by $\mathcal{D}_{u}$. The following lemma makes a statement about this set.

Lemma $2 \mathcal{D}_{u}$ is convex, with lower bound $\underline{d}_{u}$ and upper bound $\underline{d}_{u}+u$.

\section{Proof: See Appendix B.}

The intuition behind Lemma 2 is as follows: as stated above, all unemployed workers must have the same value for every $d$ within $\mathcal{D}_{u}$. In addition, for every distance that does not belong to $\mathcal{D}_{u}$, it must hold that the willingness to pay to live at distance $d$ of the unemployed drops at a slower rate than the land rent. This is true because otherwise the unemployed that live at a larger distance would be better off by re-locating themselves closer to the CBD. Failure of Lemma 2 would imply that there is a hole in the distances of unemployed workers. However, it also implies that those just above the hole must be better off than those just below the hole, since their willingness to pay for larger distance drops at a slower rate than the land rent. This is against the assumption that unemployed workers must have the same value. Lemma 2 implies that we can write $d(w)$ as

$$
d(w)= \begin{cases}(1-u) G(w) & \text { if } w<\widetilde{w} \\ u+(1-u) G(w) & \text { if } w \geq \widetilde{w}\end{cases}
$$

where $\widetilde{w}=G^{-1}\left(\frac{\underline{d}_{u}}{1-u}\right)$. Moreover, the following condition applies for the upper bound of $\mathcal{D}_{u}$

$$
\Psi_{u}^{\prime}\left(\underline{d}_{u}+u\right)=\frac{\partial \Psi_{e}\left(\underline{d}_{u}+u, w\left(\underline{d}_{u}+u\right)\right)}{\partial d}
$$

That is, employed and unemployed workers must have equal incentives to live closer to the CBD at the upper bound of $\mathcal{D}_{u}$. If for example the left-hand side 
of equation (12) would be smaller than the right-hand side of that equation, then unemployed workers have an incentive to locate themselves farther from the CBD since their loss in terms of the reduced number of job offers is lower than the reduction in terms of rents. On the other hand, if the left-hand side of (12) would be larger than the right-hand side of that equation, then employed workers have an incentive to relocate themselves farther away from the CBD. Substitution of (9) and (10) into (12) results in

$$
\begin{aligned}
\tau & =a \lambda(1-\psi) \int_{\varphi}^{\bar{w}}\left[\frac{\bar{F}(x)}{\rho+\delta+\lambda \psi s(d(x)) \bar{F}(x)}\right] d x \\
& +a \lambda \int_{\varphi}^{\widetilde{w}}\left[\frac{\bar{F}(x)}{\rho+\delta+\lambda \psi s(d(x)) \bar{F}(x)}\right] d x .
\end{aligned}
$$

Take into account that it is possible that

$$
\tau<a \lambda(1-\psi) \int_{\varphi}^{\bar{w}}\left[\frac{\bar{F}(x)}{\rho+\delta+\lambda \psi s(d(x)) \bar{F}(x)}\right] d x
$$

In that case all unemployed workers allocate themselves closer to the CBD as any employed worker and $\underline{d}_{u}=0$. This is the extreme case that was called the integrated city by Wasmer and Zenou (2002). Note that this situation is impossible to obtain when $\psi=1$ and $\tau$ positive. This is easily explained since in such a case workers who are working at the lowest wage have a higher willingness to pay than the unemployed to live at distance zero. This is because these workers have the same opportunities at the labor market as unemployed workers but have higher commuting costs. Since $\partial \Psi_{e} / \partial w$ is continuous in $w$ at $\underline{d}_{u}$, it implies that $\underline{d}_{u}$ must be positive. When $\tau=0$, then the only possible outcome is the integrated 
city equilibrium. It is also possible that ${ }^{6}$

$$
\tau>a \lambda \int_{\varphi}^{\bar{w}}\left[\frac{\bar{F}(x)}{\rho+\delta+\lambda \psi s(d(x)) \bar{F}(x)}\right] d x
$$

In that case all unemployed workers allocate themselves farther away from the CBD as any employed worker and $\underline{d}_{u}=1-u$. This is the extreme case that was called the segregated city by Wasmer and Zenou (2002). The following lemma is proven in the Appendix.

Lemma 3 The (partial) equilibrium rents are given by

$$
R(d)=R_{A}-\tau(d-1)+a \lambda \psi \int_{G^{-1}\left(\frac{d-u}{1-u}\right)}^{\bar{w}} \frac{\bar{F}(x)(d(x)-d)}{\rho+\delta+\lambda \psi s(d(x)) \bar{F}(x)} d x
$$

for $d \geq \underline{d}_{u}+u$, and

$$
R(d)=R\left(\underline{d}_{u}+u\right)-a \lambda \int_{\varphi}^{\bar{w}} \frac{\bar{F}(x)}{\rho+\delta+\lambda \psi s(d(x)) \bar{F}(x)} d x\left(d-\underline{d}_{u}-u\right),
$$

for $\underline{d}_{u} \leq d<\underline{d}_{u}+u$, and

$$
\begin{array}{r}
R(d)=R\left(\underline{d}_{u}\right)-\left(\tau+a \lambda \psi \int_{\widetilde{w}}^{\bar{w}} \frac{\bar{F}(x)}{\rho+\delta+\lambda \psi s(d(x)) \bar{F}(x)} d x\right)\left(d-\underline{d}_{u}\right) \\
+a \lambda \psi \int_{G^{-1}\left(\frac{d}{1-u}\right)}^{\widetilde{w}} \frac{\bar{F}(x)(d(x)-d)}{\rho+\delta+\lambda \psi s(d(x)) \bar{F}(x)} d x
\end{array}
$$

for $d<\underline{d}_{u}$.

Proof: see Appendix C.

Lemma 3 derives the equilibrium land rents and is based on the observation that $R^{\prime}(d)=\partial \Psi_{e}(d, w(d)) / \partial d+w^{\prime}(d) \partial \Psi_{e}(d, w(d)) / \partial w=\partial \Psi_{e}(d, w(d)) / \partial d$ for all

\footnotetext{
${ }^{6}$ This inequality can be derived after equating (9) and (10) and using $w=\widetilde{w}$ and $\widetilde{w}>\varphi$ and $\psi<1$.
} 
$d \notin \mathcal{D}_{u}$. The second equality is a direct result of the first-order condition of $\max _{w} \Psi_{e}(d, w)$. Hence, the derivation of $R(d)$ results from solving the differential equation. Unlike the situation of Wasmer and Zenou (2002), our rent function is not linear for all $d \notin \mathcal{D}_{u}$ since a decrease in distance does not only imply an improvement of search efficiency of the workers and a decrease in the commuting costs. It also implies that the wage of the worker is lower when located closer to the CBD and hence such a worker even has a higher likelihood to obtain wage offers higher than the present wage than the one who lives a little farther away from the CBD would both workers have been living at equal distance.

Figure 1 illustrates the partial equilibrium at the housing market. Rent equals $R_{A}$ at distance 1 from the CBD and gradually increases when moving closer to the CBD. There is an increasing rate at which the rent increases when moving left in the figure. This is due to the fact that $\partial \Psi_{e}(d, w(d)) / \partial d$ decreases with distance. At $\underline{d}_{u}+u$, the willingness to pay for closer locations for the unemployed equals the slope of the land rent and therefore unemployed workers find it interesting to live there. Hence, the unemployed live in between $\underline{d}_{u}$ and $\underline{d}_{u}+u$ from the CBD. Rents are linear in this interval. Workers with low wages are living in between 0 and $\underline{d}_{u}$ and these workers pay the highest rents. 


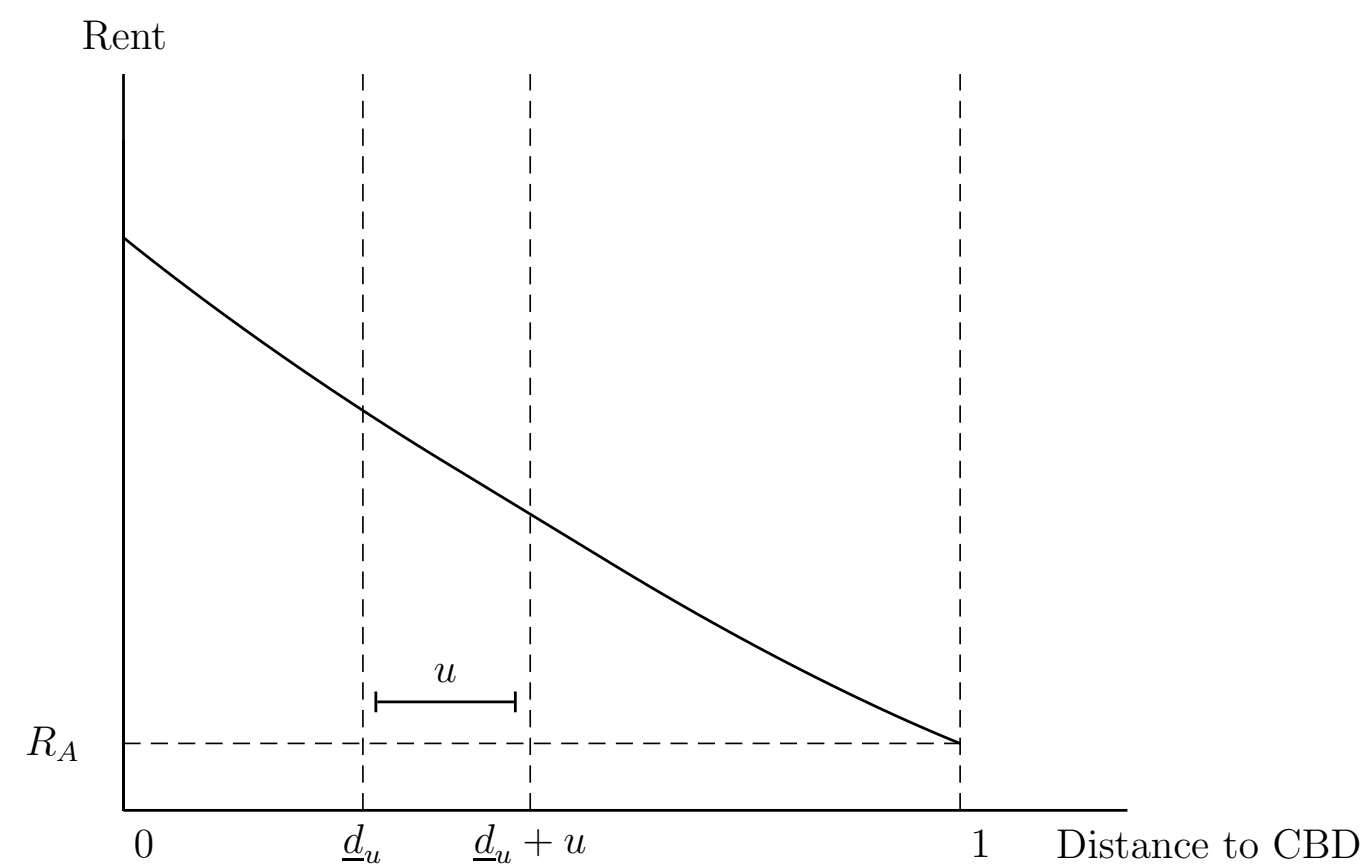

Figure 1: Illustration of the partial equilibrium at the housing market

\subsection{Partial equilibrium at the labor market}

\subsubsection{Labor market flows and stationary states}

Equalizing in- and outflow of the unemployed results in the following steady-state level of unemployment

$$
(1-u) \delta=u \lambda s\left(\underline{d}_{u}+\frac{u}{2}\right)
$$

Similarly, equalizing the in- and outflow of workers working at a wage at least paying $w$ results in

$$
\delta \bar{G}(w)(1-u)=\lambda \bar{F}(w)\left\{u s\left(\underline{d}_{u}+\frac{u}{2}\right)+(1-u) \psi \int_{\varphi}^{w} s(d(x)) d G(x)\right\} .
$$

where the left-hand side is the number of workers dismissed from a job that pays at least $w$. The right-hand side is the sum of the number of unemployed workers who find a job paying at least $w$, while the second term represents the number of 
employed workers paid less than $w$ who find such a job. Based on the definition of $s(\cdot)$ from equation (1) and the definition of $d(\cdot)$ from equation (11), we obtain

$$
\int_{\varphi}^{w} s(d(x)) d G(x)= \begin{cases}G(w) s_{0}-(1-u) a \frac{1}{2} G(w)^{2} & \text { if } w \leq \widetilde{w} \\ G(w)\left(s_{0}-a u\right)-(1-u) a \frac{1}{2} G(w)^{2}+\frac{\underline{d}_{u}}{1-u} a u & \text { otherwise }\end{cases}
$$

It implies that $G(w)$ is the root of a second-order polynomial.

\subsubsection{The reservation wage of the unemployed}

The reservation wage is determined by the following equation

$$
\rho V_{u}\left(\underline{d}_{u}\right)=\rho V_{e}(d(\varphi), \varphi)
$$

Lemma 1 states that $d(w)$ is decreasing and from the second assumption of Subsection 3.4 we know that $d(\varphi)$ can only take two values. Either it equals zero in case that $\underline{d}_{u}>0$ or it equals $u$ in the case that $\underline{d}_{u}=0$. Using equation (21) and the values of $V_{u}$ and $V_{e}$ in equations (3) and (4) and then using equation (18), we obtain that

$$
\begin{aligned}
\varphi & =b+\tau \underline{d}_{u}+\lambda[1-\psi] s\left(\underline{d}_{u}\right) \int_{\varphi}^{\bar{w}} \frac{\bar{F}(w)}{\rho+\delta+\lambda \psi s(d(w)) \bar{F}(w)} d w \\
& -a \lambda \psi \int_{\varphi}^{\widetilde{w}} \frac{\bar{F}(w)\left(\underline{d}_{u}-d(w)\right)}{\rho+\delta+\lambda \psi s(d(w)) \bar{F}(w)} d w .
\end{aligned}
$$

in the case that $\underline{d}_{u}>0$. For the case that $\underline{d}_{u}=0$, we obtain

$$
\varphi=b+\tau u+\lambda s(u)[1-\psi] \int_{\varphi}^{\bar{w}} \frac{\bar{F}(w)}{\rho+\delta+\lambda \psi s(d(x)) \bar{F}(w)} d w
$$

For the last case, $\varphi=b+\tau u$ if $\psi=1 .^{7}$ This is a standard result in on-the-job search models that states that if the opportunities of the employed and unem-

\footnotetext{
${ }^{7}$ Note that we have seen from the discussion below (14) that this combination is not possible in equilibrium.
} 
ployed are the same, then the unemployed accept anything that pays above their home production plus the additional costs that they have to make as a worker living at distance $u$ from the CBD. In the case that $\psi<1$, then they also need to be compensated for their loss of opportunities by accepting a job. The intuition behind (22) is somewhat more complicated. When $\psi=1$, then we obtain that $\varphi$ becomes strictly lower than $b+\tau \underline{d}_{u}$. This can be seen by contradiction. Suppose that workers would indeed accept only wages at or above $b+\tau \underline{d}_{u}$. Then, a worker who is working for this wage and living at exactly distance $\underline{d}_{u}$ would be equally well off as an unemployed worker. However, since $d(\varphi)=0$, she can improve her situation by living closer to the CBD and therefore she is better off as an unemployed worker contradicting the assumption that this is the reservation wage. Using the same discussion, it is also possible to show that the reservation wage must be strictly larger than $b$.

\section{$5 \quad$ Wage posting}

Using Lemma 1 and equations (19) and (20), we obtain that the value of a vacancy that posts a wage $w$ equals

$$
\rho V_{v}(w)=\frac{1-u}{v} \delta \frac{\bar{G}(w)}{\bar{F}(w)} \frac{p-w}{\rho+\delta+\lambda \psi s(d(w)) \bar{F}(w)}-\gamma .
$$

Since all firms are homogeneous, we must have that $V_{v}(\varphi)=V_{v}(w)$, or

$$
\bar{F}(w)(\rho+\delta)+\lambda \psi s(d(w)) \bar{F}^{2}(w)=\bar{G}(w) \frac{p-w}{p-\varphi}(\rho+\delta+\lambda \psi s(d(\varphi))),
$$

for all wages in between $\varphi$ and $w^{1}<\widetilde{w}$. Note that it can never be optimal to post a wage just below $\widetilde{w}$. This is because there is a discontinuity in the quit 
rate of workers at this wage level. Workers who are paid marginally below this wage live closer to the CBD than unemployed workers, while workers who are paid exactly this wage or more are living farther away from the CBD than unemployed workers. This implies that the number of workers who quit their jobs because they found a better wage offer also jumps downwards at this wage level. This is not because there is a mass point in the wage offer distribution, but just because the workers have a lower search intensity. It also implies that the profit function jumps upwards at the wage level of $\widetilde{w}$ and therefore there will be no firms paying slightly below this wage. Only if the profit margin per worker is much higher than the firms that pay above the threshold, firms are willing to pay wages below $\widetilde{w}$. The condition to be satisfied is $V_{j}\left(w^{1}\right)=V_{j}(\widetilde{w})$, or

$$
\widetilde{w}=w^{1}+\left(p-\widetilde{w}^{-}\right) \frac{\lambda a \bar{F}\left(w^{1}\right)}{\rho+\delta+\lambda s\left(\underline{d}_{u}\right) \bar{F}\left(w^{1}\right)} .
$$

The wage distribution above $\widetilde{w}$ can be obtained by using $V_{j}(\widetilde{w})=V_{j}(w)$ for every $w$ in between $\widetilde{w}$ and $\bar{w}$.

\section{General equilibrium}

We close our model by assuming that opened vacancies must have an expected profit equal to zero. Using this assumption and substitution of $w=\varphi$ in equation (24), we obtain

$$
\frac{1-u}{v} \delta \frac{p-\varphi}{\rho+\delta+\lambda \psi s(d(\varphi))}=\gamma .
$$

For the general equilibrium, we need to determine the variables $\varphi, u, \underline{d}_{u}$ and $v$, the distributions $F$ and $G$ and the rent function $R$. The restrictions for this 
equilibrium are equations (13), (16)-(18), (19), (20), (22)-(23) and (26). The wage-offer distribution, $F$, can be determined by using a particular wage-setting mechanism, such as illustrated in Section 5.

Theorem 4 Suppose that $\nu=\xi=1$ from (2) and $\psi=1$ under wage posting. Then, an equilibrium with a positive number of vacancies exists whenever

$$
p-b>\frac{2 \gamma(\rho+\delta)}{\alpha} \frac{1}{2 s_{0}-a} .
$$

Proof: See Appendix D

Condition (27) is standard and states that we can expect a positive number of vacancies if there is a sufficient difference between production at the workplace and at home. The assumption of wage posting is necessary for the proof, but can be adapted for other types of wage formation mechanisms. Unfortunately, a general proof of uniqueness is difficult for this model, but we can prove uniqueness under the conditions of Lemma 5.

Lemma 5 Suppose wage posting and $\nu=\xi=\psi=1$ and $\rho / \delta \downarrow 0$ and (27) applies. Then, the equilibrium is unique.

Proof: See Appendix E

The condition that $\rho / \delta \downarrow 0$ is standard in job search models, but obviously debatable. It is possible to obtain the following very conservative sufficient condition

$$
\frac{\rho}{\delta}<\frac{a \underline{d}_{u}}{s_{0}-a \underline{d}_{u}}
$$


Note that the right-hand side of this restriction is the percentile loss in search efficiency of the most efficient unemployed worker in comparison to search efficiency at distance zero from the CBD. To see whether this restriction is satisfied for reasonable values of $\rho, s_{0}, a$ and $\delta$ we look at estimates obtained from Ridder and Van den Berg (2003). They estimate $\delta$ to be in between 5 percent for Germany and 42 percent for the United States. Recent estimates of the discount rates indicate figures as low as 2 percent (see Laibson, Repetto and Tobacman and Gautier and Van Vuuren, 2014). It implies that workers located in the CBD should be about 2 percent more efficient in their search as the unemployed in the United States for the condition to be satisfied. In Germany, unemployed workers should have a 40 percent lower search efficiency as the workers located in the CBD. Note that the restriction is conservative since it is unlikely to hold whenever $a$ is very small whereas our model with $a=0$ has been proven to have a unique equilibrium under very general conditions.

\section{$7 \quad$ Welfare analysis}

In line with Zenou (2009), we define the social welfare function as

$$
\begin{aligned}
\Omega\left(v, \underline{d}_{u}\right) & =\int_{0}^{\infty}\left((1-u(t)) p+u(t) b-\gamma v-(1-u(t)) \tau \bar{d}_{e}\right) e^{-\rho t} d t \\
& \equiv \int_{0}^{\infty} \omega_{t}\left(v, \underline{d}_{u}\right) e^{-\rho t} d t .
\end{aligned}
$$

The first term between brackets is production of the employed workers, the second is production of the unemployed homeworkers, the third term is total costs for vacancies and the last term is the average commuting costs of the employed 
workers. We consider the situation in which the social planner faces the same search frictions as the decentralized market and investigate the outcome when the social planer is able to maximize welfare by choosing $v$ and $\underline{d}_{u}$. It implies that the social planner has as state variable $u$ with

$$
\dot{u}=\delta(1-u(t))-\lambda u(t) s\left(\underline{d}_{u}+\frac{u(t)}{2}\right) .
$$

We show in Appendix $\mathrm{F}$ that the first-order derivative of $\Omega$ with respect to $\underline{d}_{u}$ is strictly positive whenever

$$
\tau>\lambda a \frac{p-b}{\rho+\delta+\lambda s_{0}}
$$

assuming that either $\nu$ in $(2)$ or $\psi$ equals one, while it is strictly negative in the case when the $>$-sign is replaced by a $<$-sign. It implies that with the only exception of equality of the left- and the right-hand side, the social planner only prefers either $\underline{d}_{u}=0$ or $\underline{d}_{u}=1-u$. This can be explained as follows. Suppose that the social planner is able to move the unemployed workers somewhat closer to the CBD, say by distance $\Delta$. The social planner benefits from this because of the reduction in the equilibrium unemployment rate (i.e. $\left.u^{\prime}\left(\bar{d}_{u}\right) \Delta\right)$ times the difference in production between employed and unemployed workers $(p-b)$. Second, these newly employed workers increase total commuting costs (i.e. $\left.u^{\prime}\left(\bar{d}_{u}\right) \tau \bar{t}_{e} \Delta\right)$. Third, the commuting costs further increase by $\tau u \Delta$ because the existing employed workers have to commute a farther distance since there are $u$ unemployed workers that move a distance $\Delta$ closer to the CBD and hence also $u$ employed workers should move the same distance from the CBD. It can be shown that the first term is proportional to $(p-b) a \lambda$, while the last two terms are proportional to $\left(\rho+\delta+\lambda s_{0}\right) \tau$ resulting in (30). 
Gautier et al. (2010) show that among a large set of wage-setting mechanisms that they consider, only wage posting can result in an efficient outcome as long as $\psi=1$ and $\nu=\xi=1$ (i.e. the job offer arrival rate $\lambda$ equals $\alpha v$ and hence is proportional to the number of vacancies). From the discussion following equation (14), we know that for that case the decentralized market always implies that $\underline{d}_{u}>0$ even for the case that the employed only have marginally higher transportation costs as the unemployed. This automatically implies that the decentralized market outcome, including wage posting, is inefficient in this case. Still, the question remains whether the social planner would prefer a more integrated or segregated city than the market. We obtain the following result.

Lemma 6 Suppose that $\psi=\nu=\xi=1$ and $\rho<\left(a(1-u) /\left(s_{0}-a(1-u)\right)\right) \delta$. Assume that firms post wages as in Section 5. Suppose that the social planner prefers the segregated city to be the preferred outcome. Then the segregated city is also the outcome of the decentralized market.

\section{Proof: see Appendix G.}

The condition in Lemma 6 is conservative. Our simulation results indicate that the results presented in this Lemma are true even in the case that the condition is not satisfied. The proof behind the Lemma is based on the fact that when fixing $\lambda$ (and hence the number of vacancies) the location incentives of the workers are only in line with the policy maker when workers are paid their marginal productivity. In contrast, unemployed workers have a lower willingness to pay for closer locations if the wages are lower than their marginal productivity, while 
the willingness to pay for these locations for employed workers is higher. Hence, employed workers live too close to the $\mathrm{CBD}$ in the market equilibrium. This result is intuitive and implies that workers do not make socially optimal location decisions when not fully compensated for their search activities. It implies that we can expect that any model in which workers are paid monopsony wages will make this prediction. Among these are wage bargaining models and models in which firms are allowed to make counteroffers (such as in Postel-Vinay and Robin, 2002). The only reason why we still need the assumption of wage posting is to allow for endogenous vacancy creation as well. If we assume wage posting, then we can show that the unemployment rate is higher under the market than under the social planner. ${ }^{8}$ We show in Appendix G that this further increases the difference between the outcomes between the social planner and the market.

The fact that unemployment is higher under the market outcome is in line with previous results. Gautier et al. (2010) find that the unemployment rate under wage posting and $\psi=1$ is equal for the market and the planner. This implies that the wages have exactly the level under wage posting to obtain the right amount of vacancies. However, wages are higher and hence unemployment is higher in our case since firms have an additional reason to offer higher wages. In the standard wage posting framework firms offering higher wages reduce the likelihood for their workers to receive better outside offers. In our case firms that offer higher wages also reduce the number of these outside offers since better paid workers live farther away from the CBD.

\footnotetext{
${ }^{8}$ This is made formal in Lemma 7 .
} 
A couple of instruments may restore the housing decisions of the decentralized market. We propose here an instrument that reduces the costs of the unemployed workers to live closer to the CBD. This implies that condition (13) changes into

$$
\tau-\chi=a \lambda \int_{\varphi}^{\widetilde{w}}\left[\frac{\bar{F}(x)}{\rho+\delta+\lambda s(d(x)) \bar{F}(x)}\right] d x
$$

for the case that $\psi=1$, where $\chi$ is the rent reduction received by the unemployed worker in case she lives one unit closer to the CBD. It implies that she receives $(1-d) \chi$ in case she lives at distance $d$ from that CBD. This policy instrument can restore the location decisions made by the decentralized market.

\section{Simulations of the model}

We simulate our model using the same set of parameter values as Wasmer and Zenou (2002) who use a bargaining model with the bargaining power equal to 0.5 and assume that there is no on-the-job search (i.e. $\psi=0)$. This implies that $\delta=0.1, \rho=0.05, \tau=b=0.3, \alpha=p=1, \xi=\nu=0.5$ and $\gamma=0.3$. In addition, we set $\psi=1$ for the model with on-the-job search. The simulation results are listed in panel A. of Table 2. We replicate the results of Wasmer and Zenou for completeness and we report the optimal welfare for both models. ${ }^{9}$ Welfare in the Wasmer and Zenou (2002) model is optimal given the city structure and given the model parameters, but a suboptimal city structure can be chosen by the market. In fact, equation (30) is also the condition for the social planner to choose the

\footnotetext{
${ }^{9}$ See also page 531 of Wasmer and Zenou, 2002. The only difference in our table is welfare since we assume absent commuting costs for the unemployed.
} 
segregated city structure, while Wasmer and Zenou (2002) show that the market chooses this city structure whenever

$$
\tau>\frac{\gamma a v}{u s\left(\underline{d}_{u}+1 / 2\right)}
$$

Our simulations show that the market only has a suboptimal city structure when $\alpha=0.5$ and the loss in welfare is small.

Comparing both models, it becomes immediately clear that the unemployment rates are higher in our model with on-the-job search. This is not surprising, given the fact that we use a constant returns to scale contact technology implying that the search efficiency of the unemployed is frustrated by the search activities of the employed workers. Since the vacancy rate is higher under on-the-job search, this also implies that welfare should be lower. More surprising is the result that welfare increases for values of $a$ in between 0.5 and 1 . This result is also related to the choice of a returns-to-scale contact technology since even the social planner is able to obtain higher welfare levels when $a$ becomes larger. This is, a higher level of a makes search more efficient for the employed workers and this may even result in a situation in which more vacancies are needed in order to obtain the same level of unemployment.

Note that for the model of on-the-job search only the simulations with $a<0.6$ result in a completely segregated labor market (where $\underline{d}_{u}=1-u$ ), while all other cases result in a mixed city in which the unemployed are living in between the low paid and the high paid employed workers. This implies that we are, in contrast to Wasmer and Zenou (2002), able to give a good description of the city structures often found in Europe (as discussed in Section 2). 


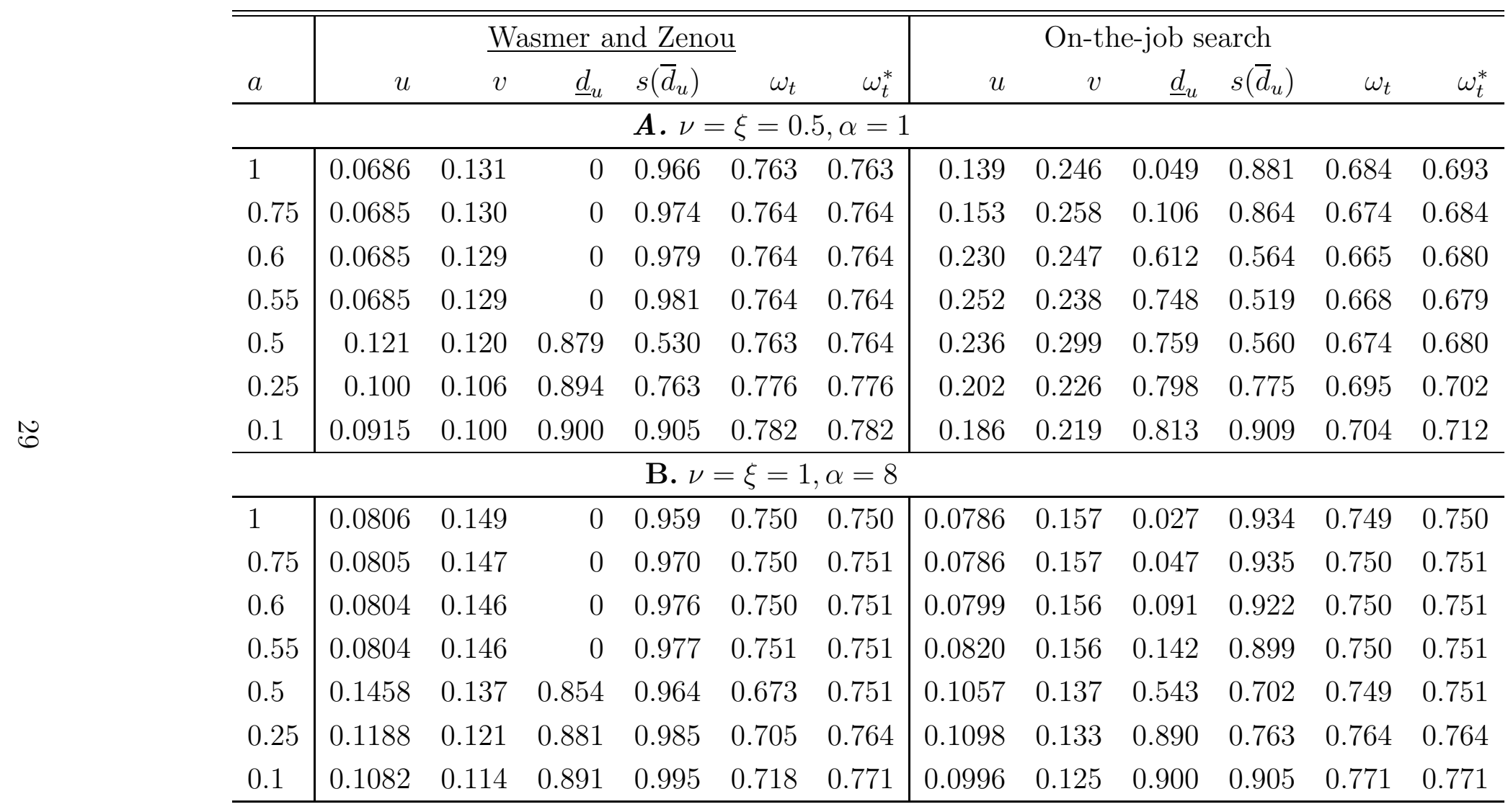

Table 2: Calibration results. $\omega_{t}^{*}$ is the per period optimal welfare. 
The comparison between the two models is complicated by the constant returns to scale matching function since employed workers congest the labor market for unemployed workers reducing their contact rate considerably. Therefore, we also look at a model with increasing returns to scale, where $\nu=\xi=1$. All other parameters are the same apart from $\alpha$ which is set to 8 here in order to obtain reasonable unemployment rates. The results are presented in panel B of Table 2. The calibration results of the two models are extremely similar for $a$ up to 0.5. For smaller values, the unemployment rate for the model with on-the-job search is somewhat lower and welfare is somewhat higher than under the model without on-the-job search. ${ }^{10}$ This implies that the high unemployment rates in Panel A were completely a result of congestion. This is also true for the difference between the optimal and market welfare. Welfare can be interpreted here as the percentage of total potential output in the case without any search frictions and commuting costs. It implies that the market looses about 25 percent of that potential production when $a=1$ and that the social planner is only able to reduce that loss by less than half a percent. It implies that the welfare loss due to suboptimal location choices of the workers is small. Hence, a policy to reduce the loss of efficiency due to suboptimal locations (such as the rent subsidy for the unemployed discussed in the previous section) cannot have a large impact.

\footnotetext{
${ }^{10}$ Note that the Hosios condition of the model without on-the-job search does not hold anymore implying that welfare within a city structure may no longer be optimal.
} 


\section{Discussion and extensions}

The main contribution of this paper is the observation that a social planner (weakly) prefers a more integrated city than the city structure that is formed by the decentralized market. This is easily explained in a model in which there are homogeneous jobs since in such a model on-the-job search does not add any value to social welfare. Therefore, the social planner is only interested in the commuting costs of the employed workers and the job finding probabilities of the unemployed workers. Hence, one of the necessary restrictions to obtain this outcome in the market is that employed workers also only consider their commuting costs when making decisions about their location. However, since there are differences in wages between identical jobs, employed workers also look at the potential to receive a higher wage offer and this explains our inefficiency result.

The question arises whether this result is robust when we loosen the assumption of homogeneity in jobs. We therefore look in this subsection at a stochastic job matching model in the tradition of Pissarides (2000, chapter 6). In order to ease notation, we assume that $p$ follows a standard uniform distribution although our results can be easily extended to any distribution. It has been shown in earlier work that wages are ranked according to their productivity and hence workers can only have different wages if they also have different levels of productivity (Gautier et al., 2010 give a formal proof). We show in this section that this does not affect our main conclusion of the inefficiency of the market.

We denote the productivity distribution of employed workers by $H$. In addition, we denote $K(p)$ for the wage that is paid for a match that yields pro- 
ductivity level $p$. Note that this function is well defined and strictly increasing since wages are ordered based on their productivity. Hence, $F(K(p))=p$ and $G(K(p))=H(p)$, where $F$ and $G$ still follow the definitions of the earlier sections and using the same techniques as in the standard version of our model, it is possible to use bid rents for the determination of the location of the unemployed workers. More in particular, we can rewrite equation (13) to obtain

$$
\begin{aligned}
\tau & =a \lambda(1-\psi) \int_{\underline{p}}^{1} K^{\prime}(x)\left[\frac{1-x}{\rho+\delta+\lambda \psi s(d(x))(1-x)}\right] d x \\
& +a \lambda \int_{\underline{p}}^{\widetilde{p}} K^{\prime}(x)\left[\frac{1-x}{\rho+\delta+\lambda \psi s(d(x))(1-x)}\right] d x .
\end{aligned}
$$

where $\widetilde{p}=H^{-1}\left(\underline{d}_{u} /(1-u)\right)$ and $\underline{p}$ is the lowest productivity level accepted by unemployed workers. The welfare function of the social planner becomes

$$
\Omega\left(v, \underline{d}_{u}, \underline{p}\right)=\int_{0}^{\infty}\left\{(1-u(t)) \mathrm{E}_{H} p+u(t) b-v(t) \gamma-\bar{d}_{e} \tau\right\} e^{-\rho t} d t
$$

Solving the planner's problem is complicated by its dependence on the equilibrium distribution $H$. Therefore, we follow an alternative: in Appendix $\mathrm{H}$ we show that for any given value of $\lambda$, we have

$$
\Omega\left(v, \underline{d}_{u}, \underline{p}\right)=\rho V_{u}^{*}\left(\underline{d}_{u}+u / 2\right)=b+\lambda s\left(\underline{d}_{u}+u / 2\right) \int_{\underline{p}}^{1} \frac{1-p}{\rho+\delta+\lambda \psi s(d(p))(1-p)} d p,
$$

whenever $\rho / \delta \downarrow 0$. In addition, we prove in Appendix I that

$$
\Omega\left(v, \underline{d}_{u}, \underline{p}\right)=\rho V_{e}^{*}(p, d(p))=p-\tau d(p)+\lambda \psi s(d(p)) \int_{p}^{1} \frac{1-p}{\rho+\delta+\lambda \psi s(d(p))(1-p)} d p
$$

whenever $\rho / \delta \downarrow 0$. This somewhat counter-intuitive result comes from the fact that when $\rho$ is small, then the social planner is only interested in the steady-state 
distribution of the workers and not in the particular state of the worker at the moment that the social planner has to make its decision. This also implies that by placing an unemployed worker closer to the CBD, the gains must outweigh the costs of placing employed workers farther away from the CBD. Hence, the condition for $\Omega$ to be maximized with respect to $\underline{d}_{u}$ is identical to the condition

$$
\frac{\partial V_{e}^{*}(p, d(p))}{\partial d(p)}=\frac{\partial V_{u}^{*}\left(\underline{d}_{u}\right)}{\partial \underline{d}_{u}}
$$

And by equation of the derivatives of (32) and (33), we obtain

$$
\begin{aligned}
\tau & =a \lambda(1-\psi) \int_{\underline{p}}^{1}\left[\frac{1-x}{\rho+\delta+\lambda \psi s(d(x))(1-x)}\right] d x \\
& +a \lambda \int_{\underline{p}}^{\widetilde{p}}\left[\frac{1-x}{\rho+\delta+\lambda \psi s(d(x))(1-x)}\right] d x .
\end{aligned}
$$

This only differs from (31) by the disappearance of $K^{\prime}(\cdot)$. Since a monopsony model in general implies that $K^{\prime}(\cdot) \neq 1$, the outcome of the social planner differs from the market equilibrium.

Note that our model is also restrictive in the linearity of the search efficiency function. Using a slight variation of the derivations in Appendix F, we obtain the following first-order condition of $\underline{d}_{u}$ for an interior solution of the social planner

$$
\tau=\frac{\lambda s^{\prime}\left(\underline{d}_{u}+u / 2\right)}{\rho+\delta+\lambda s\left(\underline{d}_{u}+u\right)+\lambda s^{\prime}\left(\underline{d}_{u}+u / 2\right)}
$$

Hence, interior solutions are possible even in the case of homogeneous workers, but with a non-linear search efficiency function. However, this is not likely to change the conclusion that the market realizes a more segregated outcome than the social planner. 


\section{Concluding remarks}

We looked at the impact of the location decision of workers when they are allowed to search on the job. Our main conclusion is that the market can never come to an efficient outcome. Even though some of our results are based on wage posting, many results only rely on the regularity assumptions of the wage-offer distribution

presented earlier in this paper. Still, our model does not allow for all types of wage-setting mechanisms such as models in which firms make counteroffers (as in Postel-Vinay and Robin, 2002). For this model, the only potential equilibrium results in a completely segregated city structure. This result is obtained from the fact that unemployed workers are offered their value of unemployment when accepting a job and hence their value does not depend on distance other than the rents. This also implies that their bid-rent function is always equal to zero. Hence, location decisions are obviously inefficient in this wage-setting mechanism as well.

\section{References}

Åslund, O, J. Östh AND Y. Zenou (2010), "How important is access to jobs? Old question improved answer", Journal of Economic Geography, 10, 389-422.

Bontemps, C., J.M. Robin and Van Den Berg, G.J., "Equilibrium search with continuous productivity dispersion: theory and nonparametric estima- 
tion", International Economic Review, 41, 305-358.

Burdet, K. And D.T. Mortensen, (1998), "Wage differentials, employer size and unemployment", International Economic Review, 39, 257-273.

Dujardin, C., H. Selod And I. Thomas (2008), "Residential segregation and unemployment: the case of Brussels", Urban Studies, 45, 89-113.

FuiJita, M. (1989), "Urban economic theory: land use and city size", Cambridge University Press, Cambridge.

Garibaldi, P. And Moen, E.R. (2010), "Job to job movements in a simple search model", American Economic Review, 100, 343-347.

Gautier, P.A., C.N. Teulings And A.P. van Vuuren (2010), "On-the-job search, mismatch and efficiency", Review of Economic Studies, 77, 245-272.

Gobillon, L., H. Selod And Y. Zenou (2007), "The mechanisms of spatal mismatch", Urban Studies, 44, 2401-2427.

Gobillon, L., T. Magnac And H. Selod (2010), "The effect of location and finding a job in the Paris region", Journal of Applied Econometrics, 26, $1079-1112$.

KaWATA, K. And Y. SATo (2012), "On-the-job search in urban areas", Regional Science and Urban Economics, 42, 715-726.

Menzio, G. AND S. SHI (2011), "Efficient search on the job and the business cycle", Journal of Political Economy, 119, 468-510.

Pissarides, C.A. (2000), "Equilibrium unemployment theory", The MIT Press, Cambridge (MA). 
Postel-Vinay, F. And Robin, J.M. (2002), "Equilibrium wage dispersion with worker and employer heterogeneity ", Econometrica, 70, 2295-2350.

Shimer, R. (2006), "On-the-job search and strategic bargaining", European Economic Review, 50, 811-830

VAn DeR KlaAuw, B. AND J.C. van OuRs (2003), "From welfare to work: does the neighborhood matter?", Journal of Public Economics, 87, 957985.

WASMER, E. AND Y. Zenou (2002), "Does city structure affect job search and welfare", Journal of Urban Economics, 51, 515-541.

Zenou, Y (2009), "Urban labor economics", Cambridge University Press, Cambridge.

\section{Appendix}

\section{A Proof of Lemma 1}

We have that $\Psi_{e}\left(d_{1}, w_{1}\right) \geq \Psi_{e}\left(d_{1}, w_{2}\right)$ and $\Psi_{e}\left(d_{2}, w_{2}\right) \geq \Psi_{e}\left(d_{2}, w_{1}\right)$. Hence for any pair of $d_{1}$ and $d_{2}$ we have

$$
\begin{aligned}
\Psi_{e}\left(d_{1}, w_{1}\right)-\Psi_{e}\left(d_{2}, w_{1}\right)= & \Psi_{e}\left(d_{1}, w_{1}\right)-\Psi_{e}\left(d_{1}, w_{2}\right) \\
& +\Psi_{e}\left(d_{1}, w_{2}\right)-\Psi_{e}\left(d_{2}, w_{2}\right) \\
& +\Psi_{e}\left(d_{2}, w_{2}\right)-\Psi_{e}\left(d_{2}, w_{1}\right) \\
& \geq \Psi_{e}\left(d_{1}, w_{2}\right)-\Psi_{e}\left(d_{2}, w_{2}\right) .
\end{aligned}
$$

Since the second-order derivatives equal zero, we have

$$
\frac{\partial \Psi_{e}\left(d, w_{1}\right)}{\partial d}=\frac{\Psi_{e}\left(d_{2}, w_{1}\right)-\Psi_{e}\left(d_{1}, w_{1}\right)}{d_{2}-d_{1}},
$$

and

$$
\frac{\partial \Psi_{e}\left(d, w_{2}\right)}{\partial d}=\frac{\Psi_{e}\left(d_{2}, w_{2}\right)-\Psi_{e}\left(d_{1}, w_{2}\right)}{d_{2}-d_{1}}
$$


Using the inequality above and $d_{2}>d_{1}$, we obtain

$$
\frac{\partial \Psi_{e}\left(d, w_{1}\right)}{\partial d} \leq \frac{\partial \Psi_{e}\left(d, w_{2}\right)}{\partial d} .
$$

But then we obtain that $w_{1} \leq w_{2}$ since we know that the cross-partial derivative of $\Psi$ is positive. Now suppose that we have equality. This implies that also the values in between $d_{1}$ and $d_{2}$ should be occupied by workers with wage $w_{1} \cdot{ }^{11}$ Hence there is a mass point at $w_{1}$. This is ruled out by the assumptions of 3.4 .

\section{B Proof of lemma 2}

Suppose that $\mathcal{D}_{u}$ is not convex. It implies that there is an interval $\left(d_{1}, d_{2}\right)$ that is not occupied by unemployed workers while $d_{1}, d_{2} \in \mathcal{D}_{u}$. Since the value of unemployed workers should be constant on $\mathcal{D}_{u}$, we have $V_{u}\left(d_{1}\right)=V_{u}\left(d_{2}\right)$. We also know that $R^{\prime}(d)=\Psi_{e}^{\prime}(d, w(d))<\Psi_{u}^{\prime}(d)$ for all $d \in\left(d_{1}, d_{2}\right)$. Hence

$$
V_{u}^{\prime}(d)=\Psi_{u}^{\prime}(d)-R^{\prime}(d)>0
$$

for all $d \in\left(d_{1}, d_{2}\right)$. But then $V_{u}\left(d_{2}\right)>V_{u}\left(d_{1}\right)$ which is a contradiction to the assumption that both should be equal.

\section{Proof of Lemma 3}

As stated in the main text, we have that

$$
R^{\prime}(d)=\frac{\partial \Psi_{e}(d, w(d))}{\partial d},
$$

Using the fact that $R(1)=R_{A}$ and substitution of (35) results in

$$
R(d)=R_{A}-\int_{d}^{1} \frac{\partial \Psi_{e}(d, w(x))}{\partial d} d x .
$$

Using (10) and changing the order of the integrals, the second term at the right-hand side of (36) equals

$$
\int_{d}^{1} \frac{\partial \Psi_{e}(d, w(x))}{\partial d} d x=\tau(d-1)-a \lambda \psi \int_{w(d)}^{\bar{w}} \frac{\bar{F}(w)}{\rho+\delta+\lambda \psi s(d(w)) \bar{F}(w)} \int_{d}^{d(w)} d x d w .
$$

Solving for the integrals and substitution of the result into (36) gives (16). For $\underline{d}_{u}<$ $d \leq \underline{d}_{u}+u$, we have

$$
R(d)=R\left(\underline{d}_{u}+u\right)-\int_{d}^{\underline{d}_{u}+u} R^{\prime}(x) d x
$$

\footnotetext{
${ }^{11}$ Suppose that $w_{1}=w_{2}$ and suppose that there is a $c \in(0,1)$ for which there is a $w^{*} \neq w_{1}$ with $\Psi\left(d(c), w_{1}\right)<\Psi(d(c), w) ; d(c)=c d_{1}+(1-c) d_{2}$. Suppose that $w^{*}>w_{1}$, then since $d(c)<d_{2}$, we have from the above that $w^{*} \leq w_{2}=w_{1}$ which contradicts that $w^{*}>w_{1}$. Suppose that $w^{*}<w_{1}$, then since $d(c)>d_{1}$ we must have $w^{*} \geq w_{1}$.
} 
and

$$
R(d)=\Psi_{u}(d)
$$

Hence

$$
R^{\prime}(d)=\Psi_{u}^{\prime}(d)=-a \lambda \int_{\varphi}^{\bar{w}}\left[\frac{\bar{F}(w)}{\rho+\delta+\lambda \psi s(d(w)) \bar{F}(w)}\right] d w .
$$

Substitution of (38) into (37) results in (17). Finally, when $d<\underline{d}_{u}$, we can use (35) to obtain

$$
R(d)=R\left(\underline{d}_{u}\right)-\int_{d}^{\underline{d}_{u}} \frac{\partial \Psi_{e}(d, w(x))}{\partial d} d x .
$$

Using (10) and changing the order of the integrals we obtain

$$
\begin{aligned}
\int_{d}^{\underline{d}_{u}} \frac{\partial \Psi_{e}(d, w(x))}{\partial d} d x & =-\tau\left(\underline{d}_{u}-d\right)-a \lambda \psi \int_{w\left(\underline{d}_{u}\right)}^{\bar{w}} \frac{\bar{F}(w)}{\rho+\delta+\lambda \psi s(d(w)) \bar{F}(w)} \int_{d}^{\underline{d}_{u}} d x d w \\
& +\int_{w(d)}^{w\left(\underline{d}_{u}\right)} \frac{\bar{F}(w)}{\rho+\delta+\lambda \psi s(d(w)) \bar{F}(w)} \int_{d}^{d(w)} d x d w .
\end{aligned}
$$

Solving for the integrals and substitution of the result into (39) results in (18).

\section{Proof of proposition 4}

For the moment suppose that $\underline{d}_{u}>0$. Using $\nu=\xi=1$, the zero-profit condition (26) can be written as

$$
u^{2} s^{2}\left(\frac{u}{2}+\underline{d}_{u}\right) \frac{p-\varphi}{u s\left(\frac{u}{2}+\underline{d}_{u}\right) \frac{\rho+\delta}{\delta}+(1-u) \psi s_{0}}=\frac{\gamma \delta}{\alpha} .
$$

For $u=0$, the left-hand side equals zero. For $u=1$, the left-hand side equals

$$
s\left(\frac{1}{2}+\underline{d}_{u}\right)(p-\varphi) \frac{\delta}{\rho+\delta} .
$$

Since $u=1$, we have that $\varphi=b+t \underline{d}_{u}$. From equation (15) we obtain that $\underline{d}_{u}=1-u=0$ and hence $\varphi=b$. Substitution of this result into the left-hand side of (40) and using the definition of $s($.$) we obtain that the left-hand side of (40) at u=1$ equals

$$
\left(s_{0}-\frac{a}{2}\right)(p-b) \frac{\delta}{\rho+\delta} .
$$

Hence equation (40) has a root under the assumptions made in the proposition. The reservation wage equation (22) has a root because if $\varphi=0$, then the left-hand side of that equation equals zero, while the right-hand side is positive. When $\varphi=p$, then the left-hand side equals $p$, while the right-hand side equals $b+t \underline{d}_{u}<b+t$. Since $p-b$ is assumed to be larger than $\tau$, it immediately implies that this equation has a root. In the case that $\underline{d}_{u}=0$, equation (40) must be replaced by

$$
u^{2} s^{2}\left(\frac{u}{2}+\underline{d}_{u}\right) \frac{p-\varphi}{u s\left(\frac{u}{2}+\underline{d}_{u}\right) \frac{\rho+\delta}{\delta}+(1-u) \psi s(u)}=\frac{\gamma \delta}{\alpha} .
$$

The arguments above still apply for this case. 


\section{E Proof of Lemma 5}

For the situation of $\psi=1$ and $\rho / \delta \downarrow 0$ we can rewrite equation (40) as

$$
u^{2} s^{2}\left(\frac{u}{2}+\underline{d}_{u}\right) \frac{p-\varphi}{u s\left(\frac{u}{2}+\underline{d}_{u}\right)+(1-u) s_{0}}=\frac{\gamma \delta}{\alpha} .
$$

The derivative of the numerator with respect to $u$ is obviously positive. The denominator can be rewritten as

$$
s_{0}-a u\left(\frac{u}{2}+\underline{d}_{u}\right) .
$$

This has a first order derivative equal to

$$
-a\left(u+\underline{d}_{u}+u \frac{\partial \underline{d}_{u}}{\partial u}\right)
$$

When $\underline{d}_{u}<1-u$, we obtain from the flow condition (19) that

$$
\frac{\partial \underline{d}_{u}}{\partial u}=\frac{a u \lambda}{\delta+\lambda s\left(\underline{d}_{u}+u\right)}>0 \text {. }
$$

In the case that $\underline{d}_{u}=1-u$ it equals one and hence $\partial \underline{d}_{u} / \partial u$ in (42) is larger than -1 . Hence the first order derivative of the denominator of (41) is smaller than $-a \underline{d}_{u}$ which is strictly negative in the case that $\psi=1$. Hence the left-hand side of (41) is strictly increasing and hence has a single root.

\section{F Derivation of equation (30)}

Using the definition of $\bar{d}_{e}$ and (11) and solving for the integrals results in

$$
\bar{d}_{e}=\int_{\underline{w}}^{\bar{w}} d(x) d G(x)=(1-u) \int_{\underline{w}}^{\bar{w}} G(x) d G(x)+u \int_{\widetilde{w}}^{\bar{w}} d G(x)=\frac{1}{2}(1+u)-\frac{\underline{d}_{u}}{1-u} u .
$$

After substitution of (43), the Hamiltonian for the maximization of $\Omega$ with respect to equation (29) equals

$\mathcal{H}=e^{-\rho t}\left[(1-u) p+u b-\gamma v-\frac{1}{2}(1-u)(1+u) \tau+\underline{d}_{u} u \tau\right]+\zeta\left[\delta(1-u)-\lambda u s\left(\underline{d}_{u}+\frac{u}{2}\right)\right]$,

where $\zeta$ is the costate variable. Note that we have

$$
\lambda=\left(s_{0}-\frac{a}{2}-(1-\psi)\left[s_{0}(1-u)+a u\left(\underline{d}_{u}+u / 2\right)\right]\right)^{\nu-1} v^{\xi} .
$$

The partial derivatives of $\lambda$ with respect to $u$ and $\underline{d}_{u}$ equal 0 whenever either $\nu=1$ or $\psi=1$. Based on this, the Euler conditions with respect to $v$ and $u$ equal

$$
\frac{\partial \mathcal{H}}{\partial v}=\gamma e^{-\rho t}-\zeta \frac{(\xi-1) \lambda u s\left(\underline{d}_{u}+\frac{u}{2}\right)}{v}=0,
$$


and

$$
\frac{\partial \mathcal{H}}{\partial u}=-e^{-\rho t}\left[p-b-\left(u+\underline{d}_{u}\right) \tau\right]-\zeta\left[\delta+\lambda s\left(\underline{d}_{u}+u\right)\right]=-\dot{\zeta},
$$

while the first-order derivative with respect to $\underline{d}_{u}$ equals

$$
\frac{\partial \mathcal{H}}{\partial \underline{d}_{u}}=e^{-\rho t} u \tau+\zeta u \lambda a
$$

Taking derivatives of equation (44) with respect to $t$, we can derive that $\dot{\zeta}=-\rho \zeta$ and substitution of this result into (45) we obtain

$$
\frac{\partial \mathcal{H}}{\partial u}=-e^{-\rho t}\left[p-b-\left(u+\underline{d}_{u}\right) \tau\right]-\zeta\left[\rho+\delta+\lambda s\left(\underline{d}_{u}+u\right)\right]=0 .
$$

Solving for $\zeta$ from this equation and substitution into (46) and rewriting results in

$$
\frac{\partial \mathcal{H}}{\partial \underline{d}_{u}}=\frac{e^{-\rho t} u}{\rho+\delta+\lambda s\left(\underline{d}_{u}+u\right)}\left[\left(\rho+\delta+\lambda s_{0}\right) \tau-a \lambda(p-b)\right],
$$

which is larger than zero because the term between brackets was assumed to be positive.

\section{G Proof of Lemma 6}

Define $\tau_{M}$ and $\tau_{P}$ as the levels of $\tau$ that equalize the left- and the right-hand side of (15) respectively (30) and define $u_{M}\left(\tau_{M}\right)$ and $u_{P}\left(\tau_{P}\right)$ as their corresponding unemployment rates. Moreover, we denote $\lambda_{P}=\lambda\left(u_{P}\right)$ and $\lambda_{M}=\lambda\left(u_{M}\right)$. We have to prove that $\tau_{P}>\tau_{M}$. We use an intuitive proof for this. Take into account that the condition that we have a completely segregated market equilibrium can also be written as

$$
\Psi_{u}(1-u)-\Psi_{u}(1)<\Psi_{e}(1-u)-\Psi_{e}(1),
$$

i.e. the worker who is at the city edge would benefit less from moving to the location of the highest paid worker (i.e. 1-u) then the best paid worker loses from moving to the city edge. Now, fix for the moment $\lambda_{M}$ and suppose that we have a situation in which all workers are paid their marginal productivity $p$. Then, using standard Bellman techniques it is possible to obtain that the value of an unemployed worker $V^{U^{*}}$ equals

$$
\rho V^{U^{*}}(d)=b-R(d)+\lambda s(d)\left(\bar{V}^{E^{*}}(p)-V^{U^{*}}(d)\right),
$$

where $\bar{V}^{E^{*}}(p)=\max _{d} V^{E^{*}}(p, d)$ and where $V^{E^{*}}(p, d)$ is the value of an unemployed worker eanring $p$ at distance $d$. In addition, we have

$$
V^{E^{*}}(p, d)=\frac{p-\tau d-R(d)+\delta \bar{V}^{U^{*}}}{\rho+\delta} .
$$

Substitution of (50) into (49) and solving for $V^{U^{*}}$ results in

$$
\rho V^{U^{*}}(d)=b-R(d)+\frac{\lambda s(d)}{\rho+\delta+\lambda s(d)}(p-b-\tau+R(d)) .
$$


The bid rents of the unemployed workers can now be found by solving for $R(d)$ in the equality $V^{U^{*}}(d)=V^{U^{*}}(1)$. It equals

$$
\Psi_{u}^{*}(d)=R_{A}+\lambda(p-b-\tau) \frac{a(1-d)}{\rho+\delta+\lambda s(1)} .
$$

The bid-rent of the employed workers can be found likewise. It equals

$$
\Psi_{e}(d)=\tau(1-d)+R_{A} .
$$

We have

$$
\Psi_{u}(1-u)-\Psi_{u}(1)<\Psi_{u}^{*}(1-u)-\Psi_{u}^{*}(1)
$$

and

$$
\Psi_{e}(1-u)-\Psi_{e}(1)>\Psi_{e}^{*}(1-u)-\Psi_{e}^{*}(1)
$$

Moreover

$$
\Psi_{u}^{*}(1-u)-\Psi_{u}^{*}(1)=\lambda(p-b-\tau) \frac{a u}{\rho+\delta+\lambda s(1)},
$$

and

$$
\Psi_{e}^{*}(1-u)-\Psi_{e}^{*}(1)=u \tau .
$$

Hence a sufficient condition for (48) is

$$
(p-b-\tau) \frac{\lambda a}{\rho+\delta+\lambda_{M} s(1)}<\tau .
$$

Solving for $\tau$ this results in

$$
\tau>\frac{(p-b) \lambda_{M} a}{\rho+\delta+\lambda_{M} s_{0}},
$$

and hence $\tau_{M}$ should be smaller than the left-hand side of this equality. Now, we still have to prove that this also holds for endogenous $\lambda$. In Lemma 7 we prove that $u_{M}\left(\tau_{M}\right)>u_{P}\left(\tau_{P}\right)$ and hence $\lambda_{M} \equiv \lambda\left(u_{M}\left(\tau_{M}\right)\right)<\lambda\left(u_{P}\left(\tau_{P}\right)\right) \equiv \lambda_{P}$. Hence

$$
\tau_{P}=a \lambda_{P} \frac{p-b}{\rho+\delta+\lambda_{P} s_{0}}=a \lambda_{M} \frac{p-b}{\rho+\delta+\lambda_{M} s_{0}}>\tau_{M} .
$$

Lemma 7 Suppose that $\psi=\xi=\nu=1$. We have that $u_{M}\left(\tau_{M}\right)>u_{P}\left(\tau_{P}\right)$.

Proof: Using the first-order condition of $v$ of the planner in (44) and (47) to solve for $\zeta$ results in

$$
\frac{\partial \mathcal{H}}{\partial v}=\gamma-\frac{p-b-\left(u_{P}+\underline{d}_{u}\right) \tau}{\rho+\delta+\lambda s\left(\underline{d}_{u}+u_{P}\right)} \alpha u_{P} s\left(\underline{d}_{u}+\frac{u_{P}}{2}\right)=0 .
$$

Substitution of $\underline{d}_{u}=1-u_{P}$, we obtain:

$$
\frac{\partial \mathcal{H}}{\partial v}=\gamma-\frac{p-b-\tau}{\rho+\delta+\lambda s(1)} \alpha u_{P} s\left(1-\frac{u_{P}}{2}\right)=0,
$$


and substitution of $\tau_{p}$ from (30) into (51) and rewriting results in

$$
u_{P} s\left(1-\frac{u_{P}}{2}\right) \frac{p-b}{\rho+\delta+\lambda s_{0}}=\frac{\gamma}{\alpha} .
$$

Substitution of the flow condition for unemployment (19) results in

$$
Q\left(u_{P}\left(\tau_{P}\right)\right) \equiv u_{P}^{2} \frac{\left(s_{0}-a\left(1-\frac{u_{P}}{2}\right)\right)^{2}}{\left(\delta+\rho u_{P}\right) s_{0}-u_{P} a\left(1-\frac{u_{P}}{2}\right)(\rho+\delta)}=\frac{\gamma}{\alpha(p-b)} .
$$

For the decentralized market we assume that $\tau=\tau_{M}$ and therefore substitute $\underline{d}_{u}=1-u$ into equation (40) to obtain

$$
Q\left(u_{M}\left(\tau_{M}\right)\right)(p-\varphi)=\frac{\gamma \delta}{\alpha}
$$

Since $\varphi>b$, we obtain that

$$
Q\left(u_{M}\left(\tau_{M}\right)\right)>\frac{\gamma \delta}{\alpha(p-b)},
$$

which implies that $Q\left(u_{M}\left(\tau_{M}\right)\right)>Q\left(u_{P}\left(\tau_{P}\right)\right)$. Note that the numerator of $Q$ is increasing in $u$, while the denominator is decreasing in $u$. Hence $Q$ is an increasing function and therefore $u_{P}\left(\tau_{P}\right)<u_{m}\left(\tau_{m}\right)$

\section{H Proof of condition 32}

Define $\widetilde{V}_{e}^{*}(p, d)$ as

$$
\widetilde{V}_{e}^{*}(p, d)=V_{e}^{*}(p, d)-\frac{\delta}{\rho+\delta} V_{u}^{*}\left(\bar{d}_{u}\right) .
$$

The standard Bellman equation of $V_{u}^{*}\left(\bar{d}_{u}\right)$ equals

$$
\rho V_{u}^{*}\left(\bar{d}_{u}\right)=b+\lambda s\left(\bar{d}_{u}\right) \int_{\underline{p}}^{1}\left(V_{e}^{*}(x, d(x))-V_{u}^{*}\left(\bar{d}_{u}\right)\right) d x
$$

Substitution of (52) into (53) and rewriting, we obtain

$$
\rho V_{u}^{*}\left(\bar{d}_{u}\right)=u b+\lambda u s\left(\bar{d}_{u}\right) \int_{\underline{p}}^{1} \widetilde{V}_{e}^{*}(p, d(p)) d p,
$$

while using the same techniques we can also derive that

$$
[\rho+\delta+\lambda \psi s(d(p))(1-p)] \widetilde{V}_{e}^{*}(p, d(p))=p-d(p) \tau+\lambda \psi s(d(p)) \int_{p}^{1} \widetilde{V}_{e}^{*}(x, d(x)) d x
$$

We prove (32) by using the intermediate step that if we prove

$$
\begin{aligned}
\rho V_{u}^{*}\left(\bar{d}_{u}\right) & =u b+(1-u) \int_{\underline{p}}^{p}(x-d(x) \tau) d H(x) \\
& +\left\{(\rho+\delta+\lambda \psi(1-p) s(d(p)))(1-u) H^{\prime}(p)\right\} \int_{p}^{1} \widetilde{V}_{e}^{*}(x, d(x)) d x .
\end{aligned}
$$


then we are done by substitution of $p=1$ in (56). We prove this by induction. The base is easily obtained by substitution of $p=p$ in equation (56) and substitute the steady-state condition $(\delta+\lambda \psi(1-\underline{p}) s(d(\underline{p})))(1-u) H^{\prime}(\underline{p})=\lambda s\left(\bar{d}_{u}\right) u$ in (54). For the induction step we need to prove

$$
\begin{gathered}
\rho V_{u}^{*}\left(\bar{d}_{u}\right)=u b+(1-u) \int_{\underline{p}}^{p+\Delta}(x-d(x) \tau) d H(x)+(1-u) H^{\prime}(p+\Delta) \times \\
\{(\rho+\delta+\lambda \psi(1-(p+\Delta)) s(d(p+\Delta)))\} \int_{p+\Delta}^{1} \widetilde{V}_{e}^{*}(x, d(x)) d x .
\end{gathered}
$$

Based on the assumption that (56) is correct. From (56), we have

$$
\begin{aligned}
\rho V_{u}^{*}\left(\bar{d}_{u}\right) & =u b+(1-u) \int_{\underline{p}}^{p}(x-d(x) \tau) d H(x)+ \\
& (\rho+\delta+\lambda \psi(1-p) s(d(p)))(1-u) H^{\prime}(p) \widetilde{V}_{e}^{*}(p, d(p)) \Delta+ \\
& (\rho+\delta+\lambda \psi(1-p) s(d(p)))(1-u) H^{\prime}(p) \int_{p+\Delta}^{1} \widetilde{V}_{e}^{*}(x, d(x)) d x .
\end{aligned}
$$

Substitution of (55) into (58) and rewriting results in

$$
\begin{aligned}
& \rho V_{u}^{*}\left(\bar{d}_{u}\right)=u b+(1-u) \int_{\underline{p}}^{p+\Delta}(x-d(x) \tau) d H(x)+(1-u) H^{\prime}(p) \times \\
&\{\lambda \psi s(d(p)) \Delta+(\rho+\delta+\lambda \psi(1-p) s(d(p)))\} \int_{p+\Delta}^{1} \widetilde{V}_{e}^{*}(x, d(x)) d x .
\end{aligned}
$$

Since the in- and outflow of workers with a productivity level exactly equal to $p$ should be equal to each other in steady-state, we have

$$
(\delta+\lambda \psi(1-p) s(d(p)))(1-u) H^{\prime}(p)=\lambda u s\left(\bar{d}_{u}\right)+\lambda \psi(1-u) \int_{\underline{p}}^{p} s(d(x)) d H(x),
$$

while also the in- and outflow of workers with a productivity level exactly equal to $p+\Delta$ should be equal to each other in steady-state or

$$
(\delta+\lambda \psi(1-(p+\Delta)) s(d(p+\Delta)))(1-u) H^{\prime}(p+\Delta)=\lambda u s\left(\bar{d}_{u}\right)+\lambda \psi(1-u) \int_{\underline{p}}^{p+\Delta} s(d(x)) d H(x),
$$

Combining equations (60) and (61), we obtain

$$
\begin{array}{r}
(\delta+\lambda \psi(1-(p+\Delta)) s(d(p+\Delta)))(1-u) H^{\prime}(p+\Delta) \\
=(1-u) H^{\prime}(p)\{\lambda \psi s(d(p)) \Delta+(\rho+\delta+\lambda \psi(1-p) s(d(p)))\}
\end{array}
$$

Substitution of (62) into (59) results in (57). 


\section{Proof of equation (33)}

This is a direct result of (55) and the definition of $\widetilde{V}_{e}^{*}$ in (52)

$$
\begin{aligned}
\rho \widetilde{V}_{e}^{*}(p, d(p)) & =\frac{\rho / \delta}{\rho / \delta+\frac{\delta+\lambda s(d(p))(1-p)}{\delta}}\left\{p-d(p) \tau+\lambda s(d(p)) \int_{p}^{1} \widetilde{V}_{e}^{*}(x, d(x)) d x\right\} \\
& +\frac{1}{1+\rho / \delta} V_{u}^{*}\left(\bar{d}_{u}\right) .
\end{aligned}
$$

Now, using $\rho / \delta \downarrow 0$ gives the desired result. 